\title{
Un ejemplar medieval del Fuero de Belorado (Burgos)
}

\author{
A medieval copy of the Charter of Belorado \\ (Burgos)
}

\author{
Inocencio CADIÑANOS BARDECI \\ Doctor en Historia \\ Investigador
}

Recibido: 23 de diciembre de 2013

Aceptado: 24 de enero de 2014

\section{RESUMEN}

El matrimonio de Alfonso I el Batallador con Urraca se convirtió en una guerra civil. El rey aragonés siempre tomó como vía de penetración en Castilla el Camino de Santiago. A su comienzo y en un desfiladero está Belorado, al que fortificó. Tras el divorcio, el rey favoreció a la villa con un fuero otorgado en 1116 con lo que se atrajo a los vecinos. En él le concede autonomía municipal y le señala un día de mercado y una feria, ésta de las más antiguas de España. El ejemplar que publicamos se corresponde con un pergamino de la Baja Edad Media que presenta un texto algo distinto a los publicados hasta ahora.

PALABRAS CLAVE: Belorado, fuero, autonomía municipal, mercado y feria, documento bajomedieval.

\begin{abstract}
The marriage of Alfonso I The Fighting with Urraca became a civil war. The Aragonese king always took the Camino de Santiago as a way to penetrate in Castile. Belorado is situated at its beginning and in a gorge, and it was fortified by the King. After the divorce, the King favored the villa with a charter granted in 1116, meant to attract the neighboring populations. It conceded municipal autonomy and set a market day and a fair, which was to be one of the oldest in Spain. The issue we publish here corresponds to a scroll of the late Middle Ages and its text is somewhat different to the ones published so far.
\end{abstract}

KEYWORDS: Belorado, charter, municipal autonomy, market and fair.

\section{RÉSUMÉ}

Le mariage de Alfonso I avec Urraca est devenu une guerre civile. Le roi aragonais a toujours pris le Camino de Santiago comme un moyen de pénétrer en Castile. Belorado se situe juste au début du $\mathrm{Ca}$ mino, et dans une gorge qui a été fortifiée par le Roi. Après son divorce, le roi a favorisé la ville avec une charte accordée en 1116 avec laquelle il voulait attirer les voisins. Elle a donné une autonomie municipale à la ville, ainsi que le signalement d'un jour de marché et une foire, une des plus anciennes d'Espagne. Le numéro que nous publions correspond à un rouleau de la fin du Moyen Âge, présentant un texte legèrement different de ceux publiés jusqu'ici.

MOTS CLÉ : Belorado, tribunaux, autonomie municipale, marché et foire. 
SUMARIO: I. Encuadre geográfico. Pedroso, en la Mesa de Belorado, cabeza del antiguo alfoz. II. Primeros siglos de la vida de Belorado. El Camino de Santiago. 1. Belorado, «agujero para la guerra». 2. El Camino de Santiago y su influencia en la villa. III. El pueblo durante el matrimonio de Alfonso I el Batallador y doña Urraca. Construcción del castillo. IV. Alfonso I otorga fuero. 1. El fuero y los artículos más destacables. 2. La nueva puebla y el municipio y su término. V. Tiempos posteriores. Confirmaciones del fuero. 1. Alfonso X traslada y repuebla de nuevo Belorado. El Fuero Real. 2. Las murallas. VI. El proceso en que se ha conservado el pergamino.

Dentro de poco se cumplirán 900 años de la concesión de un fuero a la villa burgalesa de Belorado. Los textos forales hasta hoy conocidos se reducen a una copia del siglo XVIII y los editados por Llorente y Muñoz y Romero en el siglo siguiente ${ }^{1}$. El que aquí damos a conocer es un ejemplar mucho más antiguo, del siglo XIV o XV, un pergamino que tiene el mérito de estar más cercano al original desaparecido y que nos aporta un texto algo distinto a los anteriores. El tipo de letra evidencia que es un traslado de esta época y no el original concedido por Alfonso I el Batallador, como se afirma varias veces en el escrito que le acompaña. Sí debía ser la copia más antigua conservada en el archivo municipal por los años del pleito incoado ante el Consejo Real que después diremos.

\section{Encuadre geográfico. Pedroso, en la Mesa de Belorado, cabeza del antiguo alfoz}

Se halla Belorado en uno de los extremos de la provincia, en un cruce de caminos, un desfiladero y puente que comunican la Rioja con Castilla, a la vera del río Tirón de fértil terrazgo, con numerosas huertas y molinos. Se trata de la vía que une Burgos con la Rioja (Camino de Santiago) que aquí se encuentra con el que desde la Bureba se dirige hacia los pueblos de la sierra, ganaderos y forestales. Un emplazamiento intermedio entre las cuencas del Ebro y Duero, atenazado por la Sierra de la Demanda, los Montes de Oca y la Bureba. Nuestra villa, trasladada por Alfonso X, se extiende hoy al pie de la Cuesta o Muela del Castillo.

Esta tierra estuvo muy relacionada desde antiguo con la Rioja, por ello fue conocida como la Riojilla. Los textos del pasado sitúan, frecuentemente, nuestro pueblo en la Rioja o, al menos, siempre en estrecho contacto con ella. El paso desde Castilla al valle del Ebro resulta complicado. Por el norte únicamente es accesible desde Pan-

\footnotetext{
${ }^{1}$ H. López Bernal, Apuntes históricos de Belorado, Estepa, 1907. J.A. Llorente, Noticias históricas de las tres provincias vascongadas, Alava, Guipúzcoa y Vizcaya, Madrid, 1806-1808, 5 tomos. G. Martínez Díez, Fueros locales en el territorio de la provincia de Burgos, Burgos, 1982, pp. 134-135. T. Muñoz y Romero, Colección de fueros municipales y cartas pueblas, Madrid, 1847, pp. 410-412. J. Ortega Galindo, «Belorado: Estudio de una villa en la Edad Media», Estudios de Deusto, vol. II, n 3, 1954, pp. 141-188.
} 
corbo (calzada romana de Aquitania) y por la Morcuera. Más al sur, en la Demanda, solo es posible salvarla por el desfiladero del Tirón, que controlaba Belorado, pues hasta Salas de los Infantes no existe ninguna otra vía hacia tierras de Aragón.

A principios del siglo XVIII Mateo Anguiano ${ }^{2}$ afirmaba que entre los vecinos existía la tradición de que el primer asentamiento del lugar estuvo en la Mesa, al otro lado del río, sitio cercano cuyas ruinas lo demostraban. Efectivamente, aquel punto fortificado a un kilómetro del pueblo, se denominó Pedroso. Enfrente, pero en la otra margen derecha del Tirón, nacería Belorado a mediados del siglo X, a modo de un barrio.

Se dice que la Mesa estuvo ocupada por un castro ibérico, después romanizado. Perteneció a la Autrigonia, aunque en uno de sus extremos. Los restos primeros son escasos, en cambio del tiempo del Imperio conservamos abundante terra sigilata y varias estelas. Su antigüedad queda avalada, también, con la aparición de tejas, materiales de construcción y monedas tardorromanas, lo que nos precisa la fundación o, quizá, plenitud de aquel pueblo. La región era conocida como Montes de Auca (Oca) ${ }^{3}$.

La cercana e importante calzada de entonces era la que venía de Virobesca (Briviesca), pasaba por Segisamunculum (Cerezo) para ir a Libia (cerca de Herremélluri). Se ha supuesto otra más secundaria desde Monasterio de Rodilla y Oca por Belorado a Nájera ${ }^{4}$. Los mapas detallados muestran que el camino medieval de Pedroso seguía la margen izquierda del Tirón hasta salvarle en Fresno. La fundación del nuevo pueblo necesitó de un vado o, mejor, un puente de madera para seguir la ruta actual más recta hacia la Rioja a través de un desfiladero que daría nombre a la villa.

El antiguo poblado de Pedroso tuvo un sentido estratégico muy claro. Su emplazamiento en una altura entre los cauces del Tirón y Torto, que allí se acercan y corren paralelos, ya era en sí mismo una defensa. Por esto debió de disponer de algún punto fuerte (murallas o torre) de los que no queda ningún resto. Fue centro administrativo y defensivo de aquella parcela como más al norte lo era Cerezo y al oeste Alba (después Villafranca Montes de Oca). Fueron capitales de sus respectivos alfoces. Conservamos una antigua serie de tenentes o gobernadores delegados del rey en los distritos de Pedroso, Oca, Cerezo y Belorado que nos indican los períodos de preponderancia de cada uno de estos lugares.
Tenencia de los Castillos

$\begin{array}{llc}\text { Belorado } & \text { Pedroso } & \text { Oca } \\ \text { Años } & \text { Tenentes } & \\ 913 & & \text { Gundisalvo Télliz in Cerezo } \\ 936 & & \text { Ferdinando in Cerezo }\end{array}$
${ }^{2}$ M. Anguiano, Compendio historial de la provincia de la Rioja, Madrid, 1704.
${ }^{3}$ J.A. Abasolo Álvarez, Carta arqueológica de la provincia de Burgos: I. Partidos judiciales de Belorado y Miranda de Ebro, Burgos, 1975, pp. 11-29.
${ }^{4}$ M. Pérez Avellaneda, Cerezo de Rio Tirón (Autrigón, romano y medieval), Madrid, 1983. 
Belorado

Años

1035

1040

1046

1048

1049

1081

1084

1090

1094

1099

1101

1103

1106

1110

1115 Facta carta... in castrum uel villa

qui dicitur Belforado
Pedroso

Oca

Cerezo

1116 Regnante rex Aldefonsus in Bilforad Banzo Mamme in Alba In Zereso Henegus Fortiz Azenar Sanguis in Belforado

1120 Senior Fortun Garciaz Caissar dominans

Tenentes

División del reino por Sancho III el Mayor

Senior Fortuni Enneconis cum Auka et Alba

Sancius Maceratis dominante Auche

(el mismo)

García Acenáriz dominans Auka

(el mismo)

Didaco Alvarez in Auka

(el mismo)

Alvaro Didaz in Auka et in Petroso

Comite Gomesano in Cerezo

(el mismo)

(el mismo)

(el mismo)

Alvaro Didaz in Petroso

(el mismo)

Alvar García in Oca

(el mismo)

(el mismo)

(el mismo)

Nazaiam et Belforatum atque Granione et per eum Garsion in Belforatum

1121 Calvet Ioans in Belforado

In Belforato, Garción

Caxal in Cerezo

Enneco Fortunons

1125 Garsion in Belforado

1126 Garsion in Bilforato

1127 (el mismo)

1128 (el mismo)

1129 Garsion in Belorado

Regnante Aldefonsus rex...de Belliforato usque Murella

Enneco Fortuniones in Cerezo

Regnante Aldefonsus rex...de Barbastro usque Viliforato

1130

1132 Aldefonsus Sancii in Bilforato et in Cireso

1133 Rege Adefonso regnante in toto rivo de Oia usque Belforato

Sub eius potestate Granione et Belforato et Redecilla

1134 Regnante Adefonso Sancii de Montson usque Bilforat

1139 Rodericus comes qui tenebat Belforatum

1140 Rodericus comes qui tenebat Belforatum

1177 Dominante Cerasio et Villaforato Petro Roderici

(el mismo)

1186 Didaco Lupi de Faro dominus in Belliforamine

1195

1200 (el mismo)

(el mismo)
Aldefonsus rex in Cerezo

Fortun Enecones 
Durante la Alta Edad Media Pedroso fue el centro de un alfoz y dio nombre a un famoso monasterio cercano ${ }^{5}$. Son los años de pleno avance cristiano. Su iglesia estaba consagrada a Santa María, como se nos recuerda en el fuero que estudiamos. Seguramente que la alejada y posterior parroquia de Belorado, consagrada a Santa María de la Capilla pegada al castillo, sería su sucesora y la actual imagen románica titular es aquella de Pedroso traída aquí.

Para vincular esta tierra con los reinos de Navarra y Aragón, sus reyes entregaron a San Millán de la Cogolla pequeños pero antiquísimos monasterios burgaleses, como San Félix de Oca, Sietefenestras (en Cerezo)... El más cercano a Pedroso fue el de San Miguel. Fundado en el año 759 con asistencia del rey Fruela y el obispo de Oca, Valentín, para 29 monjas nobles gobernadas por Nunna Bella. La convivencia pacífica con los cercanos musulmanes y los numerosos mozárabes riojanos que colonizaron esta tierra, explican la fundación en una fecha tan temprana y, aparentemente, todavía peligrosa. Era una avanzadilla de la repoblación de los Montes de Oca por lo que fue muy favorecido por Fernán González. Cerca estaba la residencia del obispo de Oca, una de las más antiguas diócesis de España, trasladada a Burgos pocos años antes de la concesión del fuero que tratamos.

Pedroso y Belorado convivieron paralelamente durante al menos un siglo. Todavía en 1140-43, cuando son falsificados los Votos de Fernán González, aparecen citados Petroso et Granione, pero no Belorado que debía haber alcanzado todavía escasa importancia y, en cambio, se mantenía el prestigio del antiguo Pedroso, aparte de quedar todavía allí alguna población. En el año 1049, al deslindar el término del monasterio de San Miguel de Pedroso, el rey García dejaba bien claro de Sancta Maria de Petroso uque ad pontem de Magazos, distinto de San Miguel de Pedroso. Y más adelante dice que los pobladores del monasterio tendrían comunidad de pastos con los cercanos lugares de Pedroso, Tosantos, Magazos y Puras. En el mismo documento se cita solo de paso a nuestra villa: Vitas de Villaforatu.

\section{Primeros siglos de la vida de Belorado. El Camino de Santiago}

\section{Belorado, «agujero para la guerra»}

Como hemos visto, la zona ya estaba ocupada por los cristianos a mediados del siglo VIII. Alfonso III, al finalizar el siglo siguiente, intenta consolidar el domino de la región, pero durante años los musulmanes la arrasarán periódicamente. A pesar de todo, es posible que por entonces comenzase a nacer Belorado a orillas del río Tirón. La tradición habla de una antigua iglesia donde hoy está el convento de Santa María de Bretonera, nombre quizá corrupción de Petronera. En la repoblación de la comarca debió de tener mucho que ver la llegada de los navarros, de lengua vascona. Su re-

${ }^{5}$ G. Martínez Díez, Pueblos y alfoces burgaleses de la repoblación, Valladolid, 1987, pp. 150-157. 
cuerdo ha quedado plasmado en numerosos topónimos. Pueblos de nombre vasco son Herramel, Uzquiza, Eterna (Eterrena), Ezquerra... y algunos parajes como Guménzula, Larrehedera y la fuente de Lamiturri.

La historia de la nueva población es la de una villa límite. Belorado se encuentra en una zona de tensión al ser frontera castellano-navarra en constante cambio, especialmente en la Alta Edad Media. El traslado de poblaciones en aquellos tiempos fue un hecho relativamente frecuente: Cerezo, Villafranca, Término (Santa del Cid), Briviesca e, incluso Burgos, podrían servir de ejemplo. Nacieron con fines defensivos y con los años se trasladan lentamente al llano, junto a un camino en sitio más cómodo. Allí crean un barrio que irá creciendo hasta absorber al antiguo poblado en el que permanecerá algún escaso vecino que, poco a poco, también desaparecerá, de tal manera que hasta el nombre del lugar quedará olvidado. La nueva población, sucesora de Pedroso, le sustituirá con ventaja en sus funciones estratégicas, administrativas y religiosas, especialmente tras la concesión del fuero.

Belorado aparece mencionado por primera vez en un documento espurio del año 945, pero su fundación sería anterior. Quizá surgiera a principios del siglo X, tras la ocupación cristiana del valle del Duero. De haber aparecido en el citado año, habría sido fundado por Fernán González. De todas las formas, no hay nada seguro, pues en la documentación más antigua del cercano monasterio de San Miguel no es mencionado. Se ha dicho que en tiempos de dicho conde se encontraba dentro del alfoz de Cerezo, pero la afirmación es dudosa, ya que no debía de existir tal organización traída e implantada en el siglo XI y, en todo caso, se hubiera encontrado dentro de Pedroso. El nombre presenta diferentes grafías: Belliforamen, Belliforamine, Bilforado y, en el fuero, Bilforad... que han sido traducidos popularmente por agujero para la guerra pues desde su sitio hay una cañada o agujero para ir a Rioja y Navarra. Con estos nombres aparecerá repetidamente en la historia medieval.

Belorado fue una población cuya razón de ser se encuentra en su privilegiado emplazamiento. Efectivamente, pueblo y angostura son inseparables a la hora de explicar su historia. Con el traslado y fijación del Camino jacobeo, el desfiladero se convierte en punto fundamental de comunicaciones y estratégico. A ello se unirá su condición fronteriza, que se mantendrá a lo largo de los siglos y que, cuando resurjan problemas, volverá a aparecer repetidamente como puesto militar decisivo incluso en épocas muy posteriores. Por ejemplo, todavía en una fecha tan lejana como lo es el año 1470 se obligaba a los clérigos locales a contribuir a enviar mensageros a la frontera de $\mathrm{Na}$ varra para la guarda y defensa de la tierra.

En el siglo XI esta zona del condado de Castilla pasa a vincularse a Navarra y corte de Nájera. Con Sancho III y sus hijos forman un todo. A mediados del siglo XI se encontraba en una situación un tanto imprecisa entre ambos reinos. Después quedará claramente dentro de Castilla, pero con unas líneas tan poco definidas que aún en 1305 Fernando IV y Jaime II de Aragón tenían que nombrar delegados para que demarcaran con precisión la raya entre Castilla y Aragón. 


\section{El Camino de Santiago y su influencia en la villa}

El siglo que estudiamos es de plenitud de las peregrinaciones jacobeas. Con ellas llegan el desarrollo económico, los nuevos gustos artísticos y los cambios sociales. Belorado será uno de los hitos más importantes de este caminar y uno de los que más se beneficie de ello ${ }^{6}$.

Con la fundación de Burgos en el siglo IX, la antigua calzada romana Nájera-Cerezo-Briviesca, queda casi olvidada. Mientras que Briviesca permanece estancada, Burgos crecerá y se convertirá en la nueva cabeza regional, como lo demuestra la temprana construcción de su castillo. Desde ahora uno de los puntos más importantes de relación y control entre Castilla, Montes de Oca, La Rioja, Navarra, Aragón y Francia se encontrará, precisamente, en Belorado por controlar la nueva vía.

Se asegura que fueron Sancho III el Mayor y Alfonso VI quienes trasladaron y fijaron el Camino de Santiago más al sur, por donde hoy discurre. Sería consecuencia del alejamiento del peligro musulmán. Es muy posible que esta vía comenzara a ser utilizada con anterioridad, en el siglo X, cuando los condes castellanos empujan a los musulmanes hasta el sur del Duero (912). También el otro lado de la Demanda queda libre de árabes con lo que las relaciones entre las comunidades cristianas de ambas vertientes se intensifica. Alfonso el Batallador lo favorecerá como lo indica el hecho de que, en 1126, entregue Atapuerca, in camini Sancti Yague, a la Orden de San Juan de Jerusalén a la que se asigna como una de sus finalidades la protección de los peregrinos. Dos populares santos, San Juan de Ortega, que vivió por estas tierras, y Santo Domingo de la Calzada fueron quienes construyeron numerosos puentes y acondicionaron la vía con el fin de facilitar el paso.

La primera y conocida guía de peregrinos de Aymeric nos dice que en Belorado comenzaba Castilla, cosa que también recuerda el poema del Cid al decirnos que era de castellanos Montes de Oca mojón. La fijación del Camino por esta zona resultará trascendental para las poblaciones afectadas: Logroño, Nájera, Santo Domingo, Belorado, Villafranca, Burgos... Su historia quedará indisolublemente unida a los jacobipetas, como llamaba San Juan de Ortega a los peregrinos. Una ojeada al plano de la localidad nos muestra un camino e iglesias vinculadas a la devoción a Santiago. El fuero da a entender que eran numerosos los extranjeros que se quedaban a vivir en el pueblo o, al menos, venían a comerciar.

Los siglos XI y XII son especialmente de aumento del peregrinar con la paz que garantizaba el rey, aunque no faltaron tramos peligrosos, como los bosques de los Montes de Oca, en donde el bandolerismo se mostró muy activo. La economía también irá unida al desarrollo del Camino con el imprescindible abastecimiento a los peregrinos, el establecimiento de centros asistenciales de parroquias, monasterios y

${ }^{6}$ L. Vázquez de Parga, J.M. Lacarra y J. Uría Riu, Las peregrinaciones a Santiago de Compostela, Pamplona, 1992, 3 tomos. L. Huidobro y Serna, Las peregrinaciones jacobeas, Madrid, 1950, 3 tomos. 
hospitales, que serán una consecuencia lógica. Este incremento traerá la colonización de las comarcas de la ruta y crecimiento de las poblaciones con barrios especiales de comerciantes y artesanos extranjeros. Serán los burgueses locales. El mercado y feria de nuestra villa, de los más antiguos de Castilla, se verán concurridos, también, por los judíos.

\section{El pueblo durante el matrimonio de Alfonso I el Batallador y doña Urraca. Construcción del castillo}

Con la división de Sancho el Mayor, nuestro pueblo quedaría dentro del reino navarro. Tras la batalla de Atapuerca volvió a Castilla. Con todo, en años sucesivos la documentación no deja del todo clara la pertenencia de esta parcela serrana.

El reinado de Alfonso VI resultó trascendental para Belorado, puesto que por primera vez Castilla retiene la Rioja para sí. Al morir en 1109 sin sucesión masculina el reino recae en Urraca. La mejor solución para Castilla pareció el casarla con el rey aragonés, Alfonso I el Batallador. Así se hizo en el castillo de Muñó, junto a Burgos.

Este enlace de pura conveniencia no resolverá nada y, por el contrario, dará lugar a continuos sobresaltos. En estas luchas y desavenencias se funda en buena parte la razón de la prosperidad de Belorado, cuya población se consolida por entonces, en la margen del río Tirón, con el fin de vigilar y asegurar la puerta de Burgos siguiendo el todavía incipiente Camino de Santiago. Es de suponer que Pedroso, al otro lado, quedaría casi completamente despoblado, al menos no vuelve a ser mencionado.

Urraca fue la primera mujer titular de una monarquía española. Caprichosa, sensual, voluble e inclinada al mando, pronto chocó con su marido acostumbrado a la guerra, nada fácil de manejar, brusco y autoritario. Era excelente guerrero, pero un tanto rudo en sus relaciones, poco dado a dobleces y diplomacia y tachado de misógino. Las épocas de entendimiento se alternaron con las de separación y guerra, todo lleno de pasión. El rey encerró a Urraca en el Castellar en donde la maltrató. La reina le tildó de celtíbero cruel, que la insultaba, abofeteaba y daba patadas. Logró escapar y se recrudeció la guerra entre ambos. A esto seguirían diversas concordias, vuelta a separarse y luchas y represalias entre navarro-aragoneses y castellanos.

Fracasó el intento de unir ambos reinos desde el norte de España hasta la cuenca del Tajo y ello tres siglos antes de que lo hicieran los Reyes Católicos. Podrían haber desaparecido las guerras para siempre y hubiera avanzado rápidamente la reconquista pero, como escribió Menéndez Pidal, «allí faltó todo: el genio político, la concordia conyugal y la prole. Faltaba, también, la madurez de los tiempos».

Ante tanto problema, en 1114 se llegó a la anulación del matrimonio que había durado tan solo cinco años. Urraca reinó en Castilla con muchos apuros y Alfonso se ocupó en conquistar Zaragoza. Pero no por esto dejó de titularse emperador y retener para sí las principales plazas castellanas hasta Sahagún, argumentando que aquéllos habían sido los derechos de Navarra en el pasado. Belorado sería uno de los puntos 
más decisivos en el control de esta alargada parcela castellana, pues el Camino fue siempre la principal vía de penetración aragonesa en los reinos de Urraca. La construcción de nuestro castillo será una consecuencia lógica de tales disputas. Además de su importante función estratégica en la política del Batallador y de protección social y mercantil, también garantizará las libertades y ventajas propiciadas por el fuero ${ }^{7}$.

Al describir la crónica de Alfonso VII la fortificación general de Castilla en tiempos del Batallador, relaciona a Burgos con Villafranca y a Belorado con Nájera. Los Montes de Oca estuvieron defendidos por numerosos castillos desde la Alta Edad Media: Alba (después Villafranca), Cerezo, Pedroso, Belorado, Ibrillos y Grañón, por citar los más importantes. En 1110 en que Iñigo López domina en Nájera y Grañón no se hace mención del nuestro castillo, como a menudo ocurrirá en adelante, sin duda porque todavía no estaba construido. Es posible que en 1117 Alfonso VII y su madre se hicieran con las tierras de Oca y Nájera, aprovechando la ausencia del Batallador. Un mes después éste las recupera. Para asegurar la zona, tan decisiva en sus planes estratégicos frente a Castilla, comenzaría poco antes a construir la fortaleza.

En la falda del monte fue levantada una defensa mucho más importante que la de Pedroso. El castillo ya estaba construido en 1115, pues en cierta donación de Alfonso I, estando en el pueblo, dice in castrum uel villa que dicitur Belforato, orgulloso, sin duda, de su obra. El nuevo castro estaba destinado a ser punto de enlace y control entre Castilla, la Rioja y los reinos navarro y aragonés. Por su contribución a la defensa los vecinos quedarán exentos en lo sucesivo de pagar fonsadera, como mucho más tarde será recordado: que nunca ouieron de fuero ni de uso de pechar fonsadera.

Los tenentes de Cerezo aparecen desde fines del siglo XI hasta un siglo después. Los de Pedroso (con Oca) simultáneamente al anterior, aunque dejan de hacerlo exactamente y para siempre en los días del fuero, es decir, cuando es construido el castillo de Belorado.

La tenencia estuvo, frecuentemente, en manos de los mismos señores que controlaban Nájera, Grañón, Cerezo, Ibrillos..., lo que evidencia la unidad estratégica de aquella zona, punto de contacto entre la Rioja y Castilla. Tenemos la mención del primer tenente en el año de la muerte de doña Urraca, 1126. En 1129 (y posteriores años) Alfonso I se dice rey desde Barbastro o Monzón hasta Belorado. Había perdido el control de Burgos dos años antes y otros pueblos del Camino de Santiago, pero nunca nuestra villa, que la retuvo hasta su muerte, aunque sin segregarla de Castilla. Como es sabido, sus reinos se los dejó a las órdenes militares y varias plazas a catedrales y monasterios. Por ejemplo, Belorado lo legó al monasterio de Oña - castrum Belforad cum toto suo honore-, lo que no tendría efecto. Solo con el emperador Alfonso VII, que ocupó las tierras detentadas por su padrastro e, incluso, hereda Aragón

\footnotetext{
${ }^{7}$ J.M. Lacarra, Alfonso el Batallador, Zaragoza,1978, y Documentos para el estudio de la reconquista y repoblación del valle del Ebro, Zaragoza, 1946, 1949, 1952 y 1982.
} 
y Cataluña, nuestra villa dejará de ser mencionada debido a los años de paz que durante este reinado disfrutó la región.

Las muchas ruinas actuales no permiten hacer un análisis de la construcción de la fortaleza. Debió de ser fabricada en buena parte a base de hormas, lo que explica su actual estado de absoluta ruina. La Crónica Latina le denomina torre. Sin embargo, debía ser fuerte puesto que ni las tropas que acompañaban a Fernando III ni los vecinos pudieron tomarlo a los Lara. El dibujo que trae Madoz se reduce al clásico patio de armas flanqueado por cubos en las cuatro esquinas. En el siglo XIV quedaría enlazado con las murallas del pueblo. De la conservación y reparo de la torre del homenaje, junto con un tramo de muralla, estuvieron encargados los judíos ${ }^{8}$.

\section{Alfonso I otorga fuero}

Antes y después del fuero la villa debió de regirse, también, por cierto derecho consuetudinario, que completó alguno de los aspectos de la nueva norma. Los varios ejemplos de fueros e fazannas de Belorado que conservamos son una muestra de ello. Muy antiguas, en alguna ocasión, reflejan una sociedad y costumbres rudas y hasta brutales en la aplicación de penas arbitrarias y desproporcionadas. Es evidente que, con el paso del tiempo, mayor cultura y refinamiento de costumbres, no podían seguir vigentes.

\section{El fuero y los artículos más destacables}

El fuero o carta-puebla es el reconocimiento oficial de la personalidad de un lugar'. Las franquicias y ventajas otorgadas por los reyes a determinadas villas en los años de la reconquista con el fin de facilitar su repoblación, tienen uno de sus más antiguos y mejores ejemplos en el concedido por Alfonso el Batallador a Belorado.

Los lugares realengos gozaron de fueros que les proporcionaban una mayor conciencia de su fuerza y personalidad colectiva, logrando recaer la actividad jurisdiccional en el concejo mismo, con una amplia autonomía política, además de garantizar la paz pública tan imprescindible para los negocios de la burguesía. Los fueros suelen seguir una pauta parecida en casi todos los casos. En tierras burgalesas, riojanas y alavesas... sirvió de modelo el de Logroño otorgado por Alfonso VI. Los únicos concedidos en Burgos por el Batallador fueron el de Castil de Peones y Belorado, casi simultáneamente.

El fuero otorga a la pequeña población una personalidad propia, lugar de gente libre que no estará sometido a ningún señor, como tampoco lo había estado desde su

\footnotetext{
${ }^{8}$ I. Cadiñanos Bardeci, Arquitectura fortificada en la provincia de Burgos, Burgos, 1987, y «Belorado y sus contornos», Sefarad, año 54, n 2, 1994, pp. 227-252.

${ }^{9}$ P.A. Porras Arboledas, «Los fueros medievales dentro de la producción de Alfonso García-Gallo», Cuadernos de Historia del Derecho, XVIII, 2011, pp. 115-162.
} 
fundación. Esto evidencia que los reyes siempre concedieron mucha importancia a la villa. Por este tiempo el concilium o consejo de las villas y ciudades trataba de ampliar sus competencias jurídicas y económicas así como librarse de ciertas cargas, por ejemplo la mañería, cosa que se consiguió en nuestro fuero. Durante las luchas entre Alfonso I y Urraca se mostrará palpablemente este renacer municipal liderado por los burgueses. Estos apoyarían al Batallador frente a Alfonso VII y Urraca, a quienes favorecieron el alto clero y poderosos monasterios, todos muy señorializados. Efectivamente, los burgueses de Belorado siempre estuvieron al lado del rey aragonés.

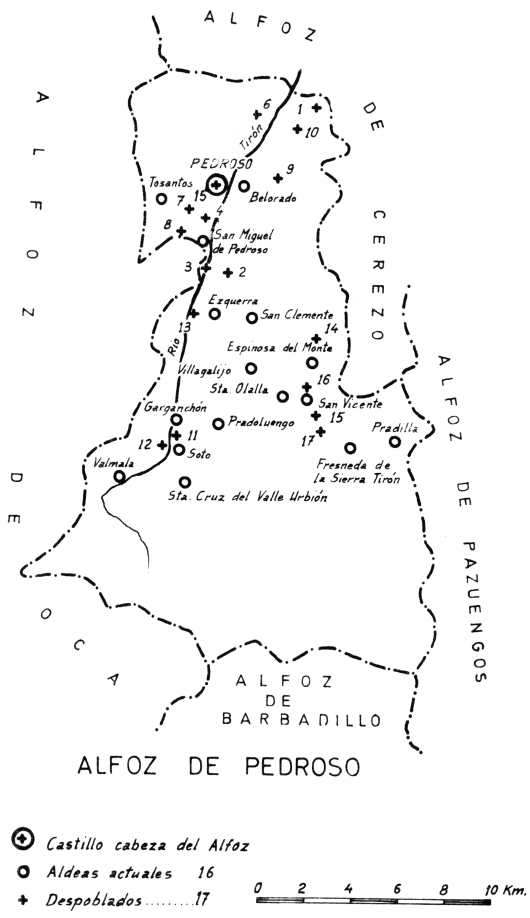

Antiguo alfoz de Pedroso, según G. Martínez Díez

Pero Alfonso no fue partidario de los mencionados movimientos municipales. Se resistió a otorgar libertades concretadas en un privilegio, a conceder alguna autonomía concejil y a señalar franquicias tributarias. Quizá temiera las revueltas contemporáneas de Sahagún, Burgos, Castrojeriz y diversas localidades gallegas. Sin embargo, ciertos intereses y también unos comunes enemigos unieron a burgueses y monarca. Efectivamente, el fuero parece mostrar el inicio de un cambio de mentalidad del rey, favoreciendo a los pueblos de los dos ramales del Camino burgalés y, en adelante, llevaría a cabo una política muy acusada de concesión de fueros y ordenación de la vida local. 
En 1116 Alfonso I proyectaba la reconquista de Zaragoza, lo que implicaba una retirada parcial del escenario castellano. Para Urraca una ocasión de recuperar el dominio del valle del Ebro. Pero el Batallador no renunciaba a su presencia en Castilla, como lo demuestra el fortalecimiento de Belorado y concesión del fuero para atraerse a sus gentes.

Nos encontramos ante el primer fuero burgalés de los denominados de francos, una adaptación del logroñés otorgado por Alfonso VI. Es un fuero breve o reducido que reproduce los puntos de aquél que más interesaban al vecindario. O sea, breves y claras normas, a semejanza de las que el rey dio contemporáneamente a Castil de Peones o Alfonso VII unos años más tarde a Briviesca, Atapuerca, Pancorbo y Cerezo. La finalidad - se nos dice- repoblarle para convertirle en cabeza de un municipio. Se trató, pues, de una práctica muy generalizada tendente a recuperar una zona gravemente castigada por las guerras, además de un medio para atraérsela a su partido.

Los populatores debieron de ser comerciantes, ciertos peregrinos asentados aquí, más algún grupo marginado. Sus fieles francos debían componer una buena parte del vecindario, junto con un numeroso retén militar de caballeros (aragoneses) a los que entrega una vivienda en el pueblo junto con los castellanos, quizá en su mayoría de origen mozárabe. Más tarde consta que habría una pequeña colonia mudéjar. Los agraciados son dichos francos, castellanos, caballeros, villanos y judíos, concediéndoles reducción de tributos, seguridades personales y garantías judiciales. Por los años del fuero los francos ocupaban un barrio especial llamado la Viña.

Aspectos más destacables:

\section{Autoridades y justicias}

El fuero es otorgado a los fidelissimos meos populatores de Bilforad. Los francos y castellanos elegirán cada uno su propio juez y ambos, omnes in unum, a los alcaldes que entiendan en las disputas. Podrían elegirlos y revocarlos sin intervención del rey ni del señor de la villa, lo que consolida la autonomía del pueblo. No se especifica límite de tiempo a su mandato. De este modo se obtendrá una de las más amplias autonomías municipales entonces conocidas en Castilla sin echar mano de las violentas exigencias de otras poblaciones. La jurisdicción abarcará desde Montes de Oca hasta Nájera. El municipio tendrá por término propio desde Otero del Cuervo hasta Terrazas y desde Villapún hasta Villafranca. O sea, un espacio algo mayor que el del antiguo alfoz de Pedroso, puesto que también comprendía una parte del de Oca. El quebrantamiento del fuero queda castigado con la altísima cantidad de 1.000 libras de oro.

\section{Casos especiales}

Toda prueba testifical en pleito habido con forasteros desde Montes de Oca a Nájera tendría que ser confirmada con tres vecinos de Belorado. No se podrá apresar a nadie si ofrece garantías. Por homicidio pagarán solo cien sueldos y nada por mañería. Por fornicación u otro cualquier delito abonarán la tercera parte. 


\section{Propiedades}

Se confirman a los habitantes sus propiedades inmuebles tanto en el pueblo como en cualquier lugar del reino, a excepción de 13 casas que el rey había entregado a sus caballeros, lo que muestra que una parte de los vecinos eran guerreros que defendían la población y su desfiladero. Las viviendas pagarán un censo anual de dos sueldos. El que viniere a poblar a Belorado tendrá libre su hacienda en toda la tierra y no se le podrán sacar prendas por causa de sus hijos ni criados sino solamente por mandado o deuda debida al rey.

\section{Contribuciones}

Que no paguen en todo el reino sino tan solo medio portazgo. En Cerezo no pagarían nada y no tendrán que aportar más de dos sueldos anuales por todo ello. En tiempos posteriores se dirá que Belorado había ayudado a poblar Santo Domingo de la Calzada, por lo que el rey le libra de pagar portazgo allí así como también en Grañón. Ello muestra el dinamismo que habían adquirido sus habitantes en la actividad mercantil en toda Castilla. Cuando cuezan en los hornos del rey, que paguen de cada treinta panes, uno. Posiblemente esto no conllevaría la prohibición de poseer hornos particulares. El obispo no podría exigir las tercias de las iglesias del pueblo y tendría que conformarse con 10 sueldos. Los vecinos elegirían clérigos a su arbitrio a quienes debían mantener pues con la limitación de los diezmos quedaban suficientes recursos para estar bien dotados. Esto explicaría que el siglo XIX todavía hubiera nada menos que 18 sacerdotes. El concejo, pues, gozó del llamado patronazgo eclesiástico a través de los tiempos. La duda posterior estuvo en si la elección de los candidatos era cosa del concejo o del cabildo de las parroquias unidas. El pleito del siglo XIX por este derecho, motivó la presentación del pergamino que aquí damos a conocer.

\section{Privilegios vecinales}

Se celebraría mercado los lunes y feria por San Miguel. Además de los peregrinos, lo demandaba una comarca de cereales, huertas, montes (madera), ganadería y actividad molinar, todos ellos excedentes propios de una tierra fértil semejante a la riojana. Fue ésta una concesión trascendental para el desarrollo de la población, pues en la Edad Media los lugares que disfrutaron de mercados fueron los que más rápidamente prosperaron. La feria, la más antigua de Castilla, también debió de ser importante, aunque con los siglos se iría apagando por la competencia de las muy cercanas de Santo Domingo de la Calzada, Nájera y Burgos. Los vecinos no pagarían montazgo por cortar ni por apacentar en los montes. Sería mantenida la costumbre relativa a la obligación de reparar los caminos, aspecto que debía cuidarse mucho en una región de terreno tan accidentado. Que puedan a su voluntad pescar y construir molinos en el río que corre desde Santa María de Pedroso hasta fin del dicho término y que puedan moler donde quisieren. A pesar de lo dicho habrá problemas con el cercano monasterio de San Miguel por tal aprovechamiento. En el transcurso de los siglos consta gran actividad molinar. 
Los vecinos recordarían en los siglos XIII y XIV que también la escribanía local les pertenecía desde encontes, como, efectivamente, lo reconoció el rey: que la hobistes siempre desque la villa fue poblada. Le fue quitada por Sancho IV, pero devuelta para refacimiento del muro de la cerca por Fernando IV y confirmada por Alfonso $\mathrm{XI}^{10}$.

La concesión y data del fuero en Cellorigo es segura, pues por estos meses se documenta la presencia del Batallador en Cerezo, Pancorbo, Villamayor... con el fin de asegurar el control de los lugares fronterizos con Álava, cuyo señor, Diego López, partidario de Urraca, estaba cercado en su castillo de Haro.

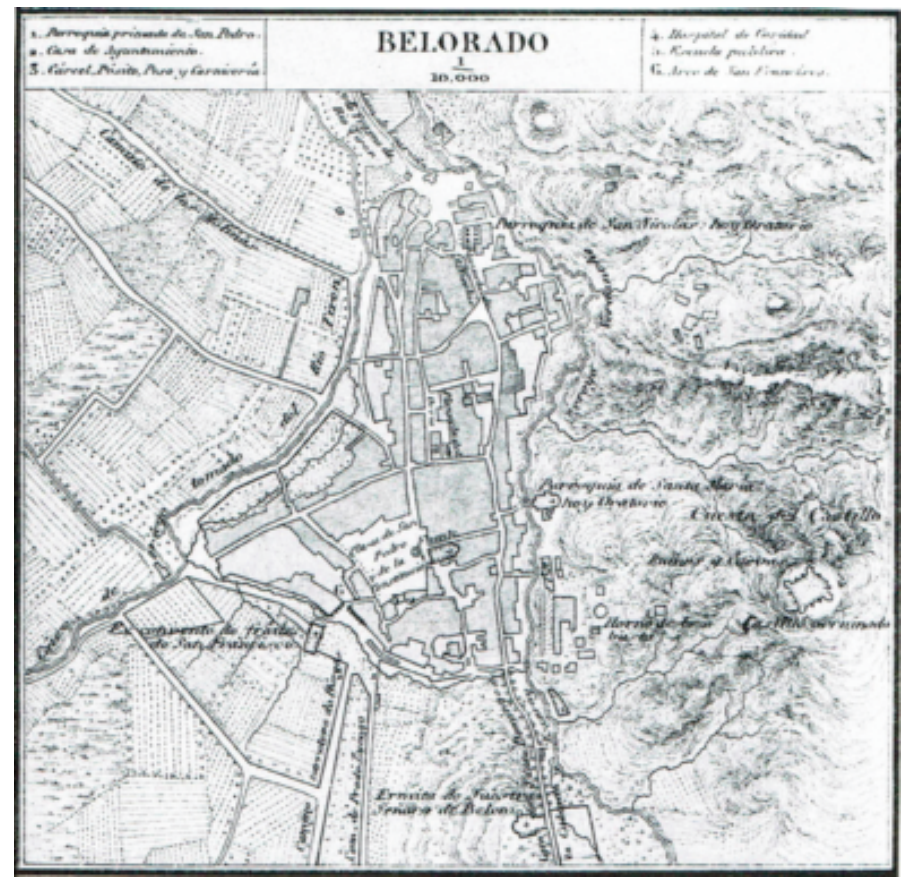

Belorado. Plano de Francisco Coello. 1868

\section{La nueva puebla y el municipio y su término}

La documentación nos habla de dos emplazamientos del pueblo: el privilegiado por Alfonso I frente a Pedroso, a la derecha del río, y la localización actual, tras la destrucción del anterior por los Lara en tiempos de Fernando III.

${ }^{10}$ Archivo Histórico Nacional, Consejos, leg. 16.841. 
La nueva puebla de Alfonso I debió de ser un lento y continuado traslado al llano, donde hoy se alza el monasterio de Santa María de Bretonera, cuya iglesia se dice que fue la antigua parroquia. En 1128, a poco del fuero, Belorado prosperaba, pues consta que ya existía dicho convento. El municipio adquirirá tal fuerza que poco más tarde será capaz de enfrentarse al poderoso monasterio de San Millán (a quien pertenecía San Miguel de Pedroso) por el aprovechamiento molinar del Tirón. Y veinte años después del fuero, varios vecinos de los cercanos pueblos de abadengo abandonaban sus hogares para instalarse en Belorado, pueblo libre, ante la ventaja de no tener que contribuir a San Millán.

El rey protegió decididamente tanto a los castellanos como a los francos que le servirán de apoyo en las luchas mantenidas en tierras castellanas. Así, la villa se convertirá en núcleo rector o cabecera comarcal de una amplia zona delimitada claramente en el fuero que, en siglos posteriores, sufrirá diversas remodelaciones hasta quedar en el siglo XVIII tan reducida que solo le pertenecerán cinco aldeas y dos barrios y a mediados del siglo XIX el lugar de Tosantos y un barrio de San Miguel de Pedroso, éste recuerdo y continuación de aquel antiguo Pedroso.

El término adjudicado en el fuero se extendía desde Villapún (Castildelgado) hasta Villafranca Montes de Oca y desde el pico de Otero del Cuervo hasta Terrazas (actualmente una granja). Otero del Cuervo habría que identificarle con el pico de Otero, junto a Pozo Negro, nacimiento del río Tirón. Algo más al norte hay una altura de casi 2.000 metros, denominada Torocuervo, que, sin duda, es una corrupción de Otero del Cuervo.

Es posible que no se tratase de un alfoz sino que se correspondiera con la jurisdicción civil y criminal en primera instancia, aunque ello no se precise en el pergamino. Las aldeas mencionadas fueron una especie de isla dentro del espacio que pocos años más tarde señale Alfonso VII a Cerezo, que parece fue una remodelación y modernización de un viejo fuero de albedrío, hoy desconocido. Ni Terrazas ni el cercano lugar de Tosantos ni todo San Miguel de Pedroso ni las aldeas del valle de San Vicente le pertenecieron en adelante a Belorado, aunque habría que matizar la afirmación pueblo por pueblo.

Se ha dudado de la existencia del alfoz de Pedroso, pero parece muy probable que sí haya existido. El apelativo de suburbio, equivalente a alfoz, ya aparece en el año 971 y como tenencia de su castillo desde el año 1090 hasta los días en que es construido y sustituido por el de Belorado. El término asignado en el fuero parece fundamentarse en él, pues resulta semejante, a excepción de su parte más occidental, hacia Villafranca Montes de Oca.

Alfonso VII es el rey que delimita los términos concejiles subordinando ciertas aldeas a las autoridades de la villa y dando lugar a los primeros concejos municipales del norte burgalés. Cuando pocos años más tarde concede fuero a Pancorbo (1147) y Cerezo (1151), les señalará un espacio jurisdiccional un tanto reñido con el nuestro. Dentro de Cerezo quedará Pancorbo y casi todas sus aldeas, llegando a penetrar en 
Valdegovía. También entrará el valle de San Vicente, al sur de Belorado, siguiendo aquel antiguo fuero que señalaba este mismo espacio jurisdiccional. La villa queda, desde ahora, como una pequeña isla con unas escasas aldeas.

Sin embargo, no todo fue tan sencillo, pues en la complicada administración judicial del Medioevo se nos presentan casos un tanto tardíos muy complejos. Por ejemplo, la jurisdicción civil de la mayoría de los lugares del valle de San Vicente dependió de Cerezo y la criminal del propio valle, manteniéndose siempre con Belorado la comunidad de pastos y leña que señala el fuero. Pero hubo excepciones y casos especiales de todo tipo.

Quizá la explicación de tanta confusión haya que buscarla en las jurisdicciones especiales o particulares, en la división de competencias y, sobre todo, en que tanto Belorado como Cerezo disfrutarán de la jurisdicción civil a prevención en muchas de las aldeas a ellos asignadas. También en el reparto de poderes entre ambos, ya que consta que en muchos casos Cerezo gozó de la jurisdicción civil y Belorado de la criminal. Alfonso VIII concedería, en 1191, al valle de San Vicente un estatuto jurídico propio, lo que complicaría aún más las cosas, aunque, en siglos posteriores, volverían a depender de Belorado, como lo demuestra la documentación del siglo XVIII relativa a la concesión de villazgos. Unos ejemplos de la situación jurisdiccional compleja bastante posterior, pero que debió de tener sus raíces en los años que estudiamos, fueron:

San Miguel de Pedroso estuvo dividido en dos barrios, uno de Belorado y otro de San Millán. Lugares lejanos como Piedrahita de Juarros, Quintanaloranco, Santovenia, Quintanilla del Monte... la jurisdicción civil perteneció a Cerezo mientras que la criminal fue de Belorado. Hubo casos más complicados, como San Juan de Ortega: el dicho logar es subjeto a la jurisdiçion de la villa de Belorado en lo criminal y en lo çevil a las villas de Cereço y Birbiesca. O Barrios de Colina, lo çevil es de la villa de Lara e lo criminal es de la villa de Velorado. También en el mencionado valle de San Vicente hubo casos complejos. En Espinosa del Monte tenía jurisdicción civil Cerezo y la criminal el propio Valle. En Ezquerra lo civil era de Cerezo y lo criminal de Belorado.

Con todo, los siglos demostrarían que fue una equivocación el despojo de Belorado y anexión a Cerezo de varias de sus aldeas. Lo acertado hubiera sido el proyecto primero del Batallador. Y es que Cerezo quedó un tanto alejado del Camino de Santiago perdiendo continuamente protagonismo en aquella zona en beneficio de Belorado que lograría encabezar un extenso partido judicial que ha llegado hasta la actualidad.

\section{Tiempos posteriores. Confirmaciones del fuero}

En el archivo municipal se conservan las sucesivas confirmaciones del fuero de Alfonso I por los monarcas hasta la Edad Moderna.

En un principio y con la paces de Támara parecía que todo iba a volver a las fronteras del pasado, pero Alfonso I no lo cumplió del todo y retuvo para sí los principales 
plazas del Camino de Santiago. En 1127 era perdido el castillo de Burgos, sin embargo, mantuvo hasta su muerte los de Castrojeriz y Belorado. Tras la conquista de la Rioja por Alfonso VII, la villa decae en importancia estratégica. Parece como si en las disputas entre Navarra y Castilla tuviera más importancia para la primera que para los castellanos.

Con Alfonso VIII las tropas frecuentan el pueblo, pues durante su minoridad el rey navarro se había hecho con la Rioja. Concede a sus vecinos el privilegio de que no se les pueda encarcelar por ningún delito. En 1178 libra a los alcaldes de la obligación fijada en el fuero de apresar a todo forastero que hubiese ocasionado una herida y, en 1202, mejorará el pago de la caloña del homicidio, que tendrá que abonar el homicida y no el concejo al uso de los de Burgos.

Durante el reinado de Fernando III el castillo cobrará especial protagonismo con la sublevación de la familia Lara, señores del pueblo. La rebeldía contra el rey les llevó a arrasar la villa como si fuera de enemigos.

\section{Alfonso X traslada y repuebla de nuevo Belorado. EI Fuero Real}

Alfonso X se preocupó de nuestro pueblo. Le trasladó de emplazamiento, intentó rodearle de murallas y le otorgó el Fuero Real, sustituyendo al fuero de 1116. Sólo lo primero sería conseguido parcialmente. El rey estuvo aquí los días 1 y 2 de febrero de 1256. Los vecinos le expondrían personalmente la decadencia y ruina del lugar como consecuencia de las luchas de su padre con los Lara.

Resulta seguro el nuevo traslado de la población. El antiguo emplazamiento a orillas del Tirón debió de resultar inapropiado por ser húmedo y difícil de defender. Las malas relaciones por aquellos años con Navarra también debieron de influir en el traslado. Ahora se intenta llevarle a una ladera, junto al castillo, formando un todo al unirlos con un cinturón de murallas. Hay varios argumentos que confirman este nuevo traslado: no existen en el pueblo restos románicos propios de los años del fuero, los templos actuales son todos de estilo gótico y hasta entonces no consta que hubiera allí más que una capilla que servía de tal a la fortaleza.

El rey dio al vecindario casi todo lo que tenía en la villa. En el mencionado año decía que por acrescerles en sus bienes et en sus franquicias porque ayan mas e valan mas... doles... todo el mio heredamiento que yo he en Bilforado... para acresçentar vuestra villa e por levarla adelante e pora fazer la puebla que yo mande fazer. Todo, a excepción de su bodega ${ }^{11}$.

Bastantes años más tarde, en 1277, permutaba ciertos bienes con Berenguela López, hija del señor de Vizcaya, dándole la nuestra bodega de Velforado con casas

\footnotetext{
${ }^{11}$ F. Blanco, Belorado en la Edad Media, Madrid, 1973. Relación de todos los privilegios y cartas de los reyes concedidos a la villa de Belorado sacada a instancia del licenciado Gil Ramírez de Arellano del arca del archivo de la villa puesta en la torre de la iglesia de San Pedro (Biblioteca Nacional, ms. 712, fol. 327 y ms. 834, fol 244 v).
} 
e molinos e huertas e viñas e heredades e con todos quantos derechos a esta nuestra bodega pertenesçen, sacado ende el logar que dizen la Mesa con lo al que nos tomamos en derredor della que tenemos para nos para facer y la villa de Velforado que mandamos alla mudar ${ }^{12}$.

Del texto se deduce que, ahora, se denominaba Mesa a la falda del monte (Muela) en que hoy se asienta la villa. El antiguo Pedroso ya estaba olvidado por completo. La población que había proyectado bastantes años antes seguía sin fundarse. Con todo, es casi seguro que por ahora comenzaran los primeros traslados. A diferencia de otras poblaciones santiaguesas, en Belorado los hospitales y fundaciones benéficas se hallan en las afueras, extramuros del pueblo, lo que muy probablemente se deba a este traslado.

Cuando a mediados del siglo XIII se redacta el Libro de los Fueros de Castilla, se recogen en él dos de los puntos del fuero de Belorado. Uno sobre los derechos que debían cobrar los alcaldes del pueblo y otro aclarando lo relativo al almacenamiento en la villa de la cosecha de vino y pan de sus aldeas. Además se reproducen varias de sus conocidas $f a z a \tilde{n} a s^{13}$. El rey otorga el Fuero Real a Burgos, que extendió a otras villas que ya disponían de fuero, como Briviesca, Miranda y Santa Gadea. Otro tanto quiso hacer aquí. El deseo de unificar los tan diversos ordenamientos jurídicos locales le empujó a ello. Pero debieron de resultar unas normas muy complejas para una vida rural sin complicaciones. Un documento del archivo municipal nos dice que el pueblo se adelantó a la generalizada protesta nobiliaria por la aplicación del Fuero Real impuesto por el rey a numerosas localidades. En septiembre del año 1272 entendiendo que el conceio de Bilhorado se agraviava del fuero del libro que les nos dieramos e por otras cosas que solien aver por fuero en tiempo de los otros reyes et temen que nos que los sacaramos ende... otorgamos les aquel fuero que ovieron en tiempo de... los otros reyes.

Con los sucesores del rey Sabio nuestro pueblo conservaría la importancia estratégica del pasado. Sancho IV la visita varias veces en viaje hacia la Rioja. Entregó al pueblo todas las pertenencias de la corona y les redujo la marzazga, en compensación de otra grave destrucción ocurrida durante su reinado.

\section{Las murallas}

El traslado proyectado por Alfonso X debió de llevarse a efecto lentamente y prolongarse hasta el reinado de Sancho IV, como lo declararía Alfonso XI al concederle ciertos privilegios, afirmando que se trataba de un lugar que todavía era poco. Y ello no solo debido a la lentitud y dificultades de la construcción de un nuevo poblado sino a devastaciones posteriores.

\footnotetext{
${ }^{12}$ AHN, Sellos, carp. 10 (4).

${ }^{13}$ G. Sánchez, Libro de los Fueros de Castiella, Barcelona,1981.
} 
En 1301 Fernando IV confirmaba el fuero del Batallador por el cual los vecinos eran libres y exentos de ser presos en ninguna parte por ningún delito que cometieran ni deuda debida, sino que fueran remitidos a las justicias de la villa, y les libraba de pagar fonsadera como lo había ordenado Fernando III. Dos años después añade algunos privilegios y devolviéndoles la escribanía con el fin de que completase su sistema defensivo. Los vecinos advirtieron que iba contra su fuero el que alguien pudiera hospedarse dentro de la cerca en tanto que ésta no estuviera concluida. Así les fue reconocido.

Alfonso XI nos recuerda que la villa fue destruida y quemada en tiempos de Sancho IV y que los vecinos la tornaron a poblar y la defendieron a su costa. Les libra, por ello, de la actuación de cualquier juez extraño y que ninguna mesnada pueda hospedarse dentro de sus muros.

Pedro I quitaría el señorío del pueblo a su madre por apoyar a su hermanastro. Revirtió a la corona y confirmó al vecindario los antiguos privilegios del fuero como nombrar alcaldes, jurados, escribano, mayordomo y merino. Agradecida, la villa fue su partidaria en las luchas de ese reinado y sufriría los asaltos del pretendiente, quedando destruida e incendiada en 1366. Fue repoblada por Enrique II y, después, entregada a hermano Sancho, a pesar de las promesas en contra, perdiendo su antigua libertad municipal para siempre.

La ricahembra doña Leonor, hija de dicho Sancho y mujer del rey aragonés, consta como señora del pueblo en el siglo XIV. Después la villa queda un tanto marginada de la actividad política. Solo durante las intrigas de los Infantes de Aragón volverá a cobrar protagonismo, pues Juan II tuvo que acudir al pueblo, que estaba en poder del navarro, quien de ninguna manera quería perder aquel puesto fortificado.

El paso al señorío de los Velasco a mediados del siglo XV se mantendrá hasta tiempos modernos. El matrimonio de los Reyes Católicos será el punto de inflexión de la pérdida definitiva del alto valor estratégico alcanzado por Belorado en el siglo XII.

\section{El proceso en que se ha conservado el pergamino}

Son pocas las variantes entre los distintos ejemplares del fuero que conocemos. Donde más diferencias hemos encontrado respecto al nuestro ha sido en los confirmantes y alguna palabra suelta. Se deben, sin duda, a una deficiente transcripción que se ha tratado de corregir con ciertas notas. El presente texto tiene, sin duda, el valor de ser el más cercano al original, por lo que hemos creído que resultaba conveniente darlo a conocer.

Posiblemente el pergamino de Alfonso I desapareció durante las guerras de los Trastamaras. Consta que en las Cortes de 1392 los delegados de Belorado expusieron que la iglesia de San Pedro, donde se custodiaba su archivo, fue robada en tiempos de Enrique II desapareciendo los privilegios.

En 1446 se unen las varias iglesias del pueblo reduciendo sus servidores a 12 clérigos, tres diáconos y seis acólitos. Las rentas no daban para más. Se pleitea con el 
concejo sobre las presentaciones de los beneficios. Bastantes siglos después volvía a repetirse y la Cámara real recordaba lo siguiente:

Pleito que se siguió en el Tribunal Supremo entre los vecinos de Belorado con el abad y cabildo de curas y beneficiados sobre patronato y modo de proveer los beneficios de ella. Principió en 31 de marzo de 1796. Los vecinos expusieron los graves perjuicios que experimentaban el pueblo y sus hijos patrimoniales por el abuso que el cabildo procedía en la provisión de beneficios. Si no pudiera probarlo que en adelante lo proveyesen el arzobispo según el concilio de Trento en los patrimoniales o naturales de la villa más idóneos. Y de tener razón el cabildo que se proveyesen por concurso de méritos.

Y remitió el pleito al arzobispo.

La villa presentó el fuero concedido por Alfonso I de Aragón. Aseguraba que era el original, afirmación que no puede admitirse. Probablemente se trata de un traslado del siglo XV, cuando el citado pleito. Por este privilegio — decía el pueblo- se manifestaba que pertenecía a la corona el nombramiento de los beneficios en disputa.

El provisor diocesano dio la razón al cabildo con la precisa calidad de que los presentados en lo sucesivo hubiesen de tener el orden de prima tonsura y ser examinados por las sinodales, según la práctica de aquel arzobispado. La sentencia definitiva fue pronunciada en Madrid el 17 de agosto de 1816:

No ha lugar a lo solicitado en estos autos por la justicia, ayuntamiento, concejo, vecinos de la villa de Belorado y el cabildo de curas y beneficiados de las parroquias unidas de la misma villa se arregle en lo sucesivo para la presentación de beneficios según lo declarado por el provisor del arzobispado en $1800^{14}$.

Todo ello teniendo presente el antiguo fuero otorgado por Alfonso I el Batallador.

\footnotetext{
${ }^{14} \mathrm{AHN}$, Consejos, leg 16.841. Certificación del abad y cabildo de curas y beneficiados de las yglesias unidas de la villa de Belorado del pleito que ha seguido con la justicia, regimiento y vecinos de la misma y el señor fiscal sobre derecho de patronato y presentación de los beneficios de ellos. Año 1818.
} 


\section{APÉNDICE}

1116, agosto 6 (domingo). Cellorigo

Alfonso I el Batallador concede fuero a Belorado.

Archivo Histórico Nacional, Consejos, legajo 16.841. Pergamino.

(Christus) Sub Christi nomine, ego Aldefonsus, gratia Dei rex magnificus inperator, habeo fidelisimus meos pobladores de Bilforad, volo ut omnibus hominibus presentem licet cartulam sint notum qualiter ego supra memoratus rex dompnus Aldefonsus uobis prefatos fideles meos pobladores francos et castellanos de Bilforad. Ita dono uobis ut populetis pro tale foro:

[1] Ut per homicidium detis centum solidos et non detis maneria et per homicidium neque per fornicium neque per furtum neque per ullam calumpniam dictam uel factam non detis nisi tertiam partem.

[2] Et sigildum [exidum] habeat Bilforad de Oter del Coruo usque ad Terrazas et de Villa de Pun usque ad Uillafranca et riuulo que currit habeatis solutum per piscare ac molinis facere ad totum uestrum talentum uel uoluntate de Sancta Maria de Pedroso iuso usque de scripto termino.

[3] Et in tota mea terra non detis nisi medium portaticum et [roto: in meos] montes non detis montatico non per taliare neque per pacere.

[4] Et in Cereso non detis portatico.

[5] Et de unam quisque causam [casam] non detis in anno nisi duos solidos in tempore Sancti Micaelis.

[6] Et die lunis habeatis uestro mercato. Et de anno in anno feriam habeatis in diebus Sancti Micaelis.

[7] Et qui uenerit populare in Bilforad sua hereditate soluta habeat in tota mea terra. Et nulla ausus fiat ut contrariam faciam illum.

[8] Et per nullo homine neque pro uestro seniore [saione] non soluatis pendram nisi fuerit pro uos ipsos uel pro uestro debito.

[9] Et ubi uolueritis mollere, moliatis.

[10] Sed in meos fornos cocatis et de $\mathrm{xxx}^{\mathrm{a}}$ panes in fornatico unum date. Et fornos totos meos fiant.

[11] Et qui morador uel polador fuerit in Bilforad francos e castellannos, cauallarios ac uillanos unum forum habeatis de calumpniam dare et medianedo ad nostra porta [parte]. Et fidiatores date de uestros hostios [honores].

[12] Et iudeo cum christiano et christiano ad iudeo qualem liuorem fecit talem pectet, sed duabus partibus fiant in terra pro anima mea sicut supra escriptum est.

[13] Et for[o] de camino sicut constitutum habuistis antea de vendere [vereda] ac reparare.

[14] Et nullus de uobis qui fidiatores potuerit dare non fiat presus neque in carcerem missus.

[15] Et uos francos mitatis iudice franco ad uestrum talentum et castellanos similiter tollite ac mittite uestro iudice ad uestro talento de uestra gente. Et omnes in unum mittatis alcaldes ad discurrendum iuditium.

[16] Et qui uobis pro iudicium aut pro debitum uel per aliquam causam uoluerit firmare, uos firmet uos de Monte de Oka usque ad Nagera cum III homines qui fiant de populatione qui medianedo e omni foro habeat sicut supra diximus. 
[17] Et de uestras ecclesias non detis alias tercias ad episcopum nisi decen solidos in anno et uestros clericos ad uestrum talentum.

[18] Et uos meos fideles francos concedo uestras honores intus e foras sicut promisi uobis antea extra solum XIII casas tollo uos inde quas dedi ad meos cauallarios.

Et si aliquis homo uel femina ad disrumpendum uenerit ista carta, in primis pariat mil libras purissimo aureo ad me regem supra memoratum et post obitu meo qui regnet concedat, querat e accipiat et postea qui hoc contradicat, extraneus permaneat ad fide Christi et cum Datam [et Abiron] quos terra uiuos absorbuit in inferno, particeps fiat et cum Iuda traditore in inferno inferiore, amen.

Facta carta notu die dominica VIII ${ }^{a}$ idus augusti sub era M.C.L.IIII, regnante rex Aldefonsus in Arachona, Panpilona, in Nagera in Cereso et Bilforad, in Karrion, Santi Facundi et in Toleto. Et sub eius dominante Açenar Sanz. In Cereso Henegus Fortiz, Dominico Micael merino. Garcia Fortum et Obieco Dominguez discurrente iudicio. Et testes ad roborandum tradimus comite senior Ramon de Paliars, Petro Nunniz, senior Lop Garcia de Estella, senior Porta Guerra, senior Belenguer de Monson, Sanz Iohannys tenente Poza, senior Sanz Acenariz de Funes, senior Jussion de Sancho Fursionis, Justinio Cortes.

Ego Petrus scriptor regis concedo et laudo hanc cartam sicut superius est scriptum et hoc signum [signo con cruz] fecit. Roborata ad nuncupata per manu imperatori regis Adefonso.

In Cellarigo die sol. 